\title{
Study of Impact of Linke Turbidityon Solar Radiation over Kathmandu Valley
}

Shrestha Prakash M, Poudyal Khem N., Chapagain Narayan P., Karki Indra B.

\begin{abstract}
Population growth, mechanization, and industrialization have now made humanity the equivalent of other natural processes in its effect on air-pollution levels and associated climatic change. Linke turbidity is an important parameter for assessing the air pollution of Kathmandu (Lat.:27.72 ${ }^{\circ} N$, Long.: $85.32^{\circ} \mathrm{E}$ and Alt.: $1350 \mathrm{~m}$. above sea level). The Because of the unavailability of spectral measurements, a model has been used to estimate the Linke turbidity factor $\left(T_{L}\right)$ from broadband measurements of Global Solar radiation on 2012 by using CMP6 paranometer. The average value of extinction coefficient $(K)$ and Linke turbidity are $0.69 \pm 0.03$ and $5.53 \pm 0.23 \$$ respectively, which can be compared with other sites around the world. Relationship between turbidity co-efficient with meterological parameters (humidity, temperature and water contained) have been investigated further.
\end{abstract}

Keywords: Air mass, clearness index, extinction coefficient, Linke turbidity, meteorological parameters

\section{Introduction}

Sun is the closest star from the Earth and hence solar energy is the fundamental as well as primary source of energy.Main source of energy of Sun is nuclear fusion. This reaction causes four hydrogen nuclei to fuse together to form one helium nucleus. The helium particle is about 0.7 percent less massive than the four hydrogen nuclei. Thereleased energy is 26.7MeV.The irradiance at the surface of theSun is $6.3 \times 10^{7} \mathrm{~W} / \mathrm{m}^{2}$. Solar energy is the largest renewable resources for earth.Atmospheric turbidity if opacity of atmosphere. It indicates air pollution .Linke turbidity is one of index used to measure atmospheric turbidity.Study of Linke turbidity and its dependence on different meteorological parameters are used in agriculture, Hydrology, Climate change.

Nepal is a land-locked south- east Asian mountainous country with a large area of beautiful landscape situated between latitudes of $26.36^{\circ} \mathrm{N}$ to $30.45^{\circ} \mathrm{N}$ and longitudes of $80.06^{\circ} \mathrm{E}$ to $88.2^{\circ} \mathrm{E}$. The elevation of the country ranges from $60 \mathrm{~m}$ to $8848 \mathrm{~m}$ within a span of $200 \mathrm{~km}$ from south to north and about $800 \mathrm{~km}$ from east to west [1].Nepal is situated between two giant industrial countries India and China and their industrial byproduct can directly affect theconcentrations and depletion of ozone concentration over Kathmandu Valley. Therefore, detail study of atmospheric turbidity is very important.Nepal lies in 
sunbelt (latitude $15^{\circ}$ to $35^{\circ}$ ).Thus it receives ample solar radiation through the country, which varying from $12.93 \mathrm{MJ} / \mathrm{m}^{2} /$ day to $22.48 \mathrm{MJ} / \mathrm{m}^{2} /$ day. Annual solar isolation is 3.6to $6.2 \mathrm{kWh} / \mathrm{m}^{2} /$ dayand sunshine duration is 300 days in Nepal[2].In fiscal year $2010 / 011,425.16$ TJ energy is consumed in Nepal in which ,Tradition fuel is $83.7 \%$,commercial fuel is $15.5 \%$ and renewable energy is $0.8 \%[3] .4,37,614$ vehicle register in Nepal in BS 2074/075 [4]. Air pollution is created by vehicle and combustion of fuel .

Kathmandu (lat.: $27.72^{\circ} \mathrm{N}$, long.: $86.37^{\circ} \mathrm{E}$ and Alt. 1350 masl) is capital city of Nepal .Kathmandu valley is combination of Kathmandu district,Lalitpur district and Bhaktapur district covers area 893 sq. km .Kathmandu valley is bowl-shaped. Kathmandu valley is surrounded by four mountain ranges: Shivapuriat north, Phulchowkiat south, Nagarjun at north-west and Chandragiri at west as shown in figure 1:.Population and population density are $2,510,788$ and $2793 \mathrm{~km}^{-2}$. Respectively [5].The maximum and minimum GSR of $25.3 \mathrm{MJ} / \mathrm{m}^{2} /$ day and $14.6 \mathrm{MJ} / \mathrm{m}^{2} /$ day were observed in May and January respectively.The annual average solar energy measuring $5.19 \mathrm{kWh} / \mathrm{m}^{2} /$ day is found in Kathmandu from 2009 to 2010 [6].The average values attenuation coefficient in Kathmandu during the pre-monsoon period of 1999 are found to be $0.602 \pm 0.022$ respectively[7] .

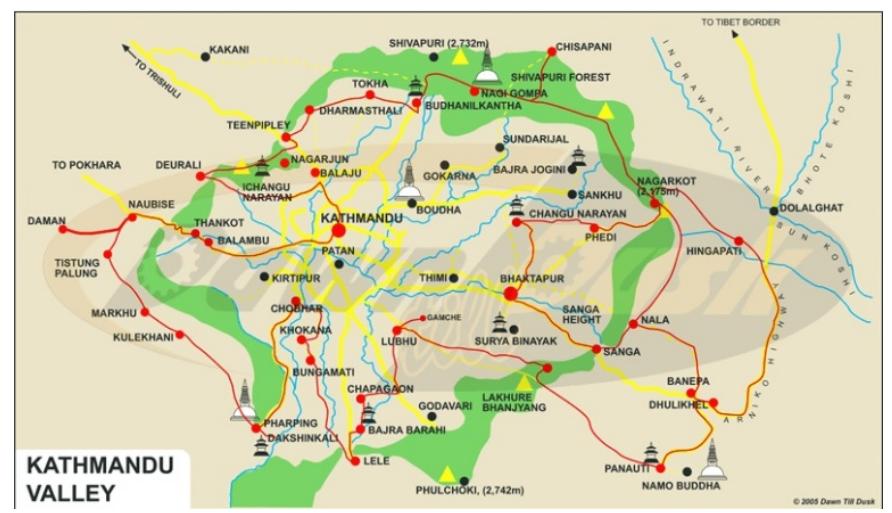

Figure 1:Map of Kathmandu Valley [source:www.lahistoriaconmapas.com/atlas/]

\section{Methodology and material}

The extraterrestrial solar radiation on outermost layer of atmosphere $\left(\mathrm{H}_{\mathrm{o}}\right)$ is a function of latitude $(\phi)$,eccentricity of orbit of Earth about $\operatorname{Sun}(\varepsilon)$,solar zenith angle $\left(\theta_{z}\right)$,solar hour angle $(\omega)$ and independent of other local parameters. As the solar radiation passes through the earth's atmosphere, it is further modified by processes of scattering, reflection and absorption due to the presence of cloud, aerosol and atmospheric particles. Solar energy incident on a horizontal surface of ground $\left(\mathrm{H}_{\mathrm{g}}\right)$ is very much location-specific and less than the extraterrestrial radiation.It is affected by physical and meteorological parameters.It is 
exponentially attenuated in atmosphere with air mass(m) and attenuation(extinction ) coefficient $(\mathrm{K})$.

According to Bougure-Lembertlaw,clearness index $\left(\mathrm{K}_{\mathrm{T}}\right)$ is, $[8,9,10]$

$K_{T}=K_{g} / R_{Q}=e^{- \text {Rix }}$

Where

$H_{Q}=F_{s e} \pi \cos _{2}$

ecoentipfortsg $(\sigma)=\left[1+0,088 \operatorname{sog}\left(\frac{300}{808} m_{i}\right)\right]$

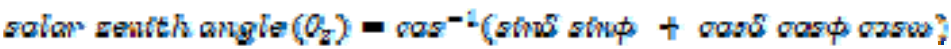

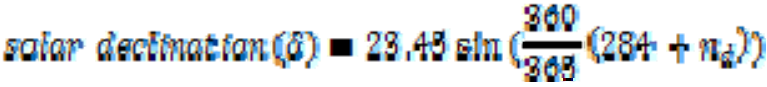

$\mathrm{I}_{\mathrm{sc}}=$ solar constant $=1367 \mathrm{~W} / \mathrm{m}^{2}[11]$

$\mathrm{n}_{\mathrm{d}}=$ no. of day of year(DOY)

According to Bason[12,13], Linke turbidity $\left(\mathrm{L}_{\mathrm{T}}\right)$ is

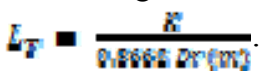

$\operatorname{Dr}(\mathrm{m})$ is Rayleigh optical thickness as a function of the relative optical air mass $\left(\mathrm{m}_{\mathrm{a}}\right)$. The relative optical air mass $\left(\mathrm{m}_{\mathrm{a}}\right)$ is described by Kasten (1966) using the solar zenith angle $\left(\boldsymbol{\theta}_{z}\right)$, altitude and atmospheric pressure $(\mathrm{P})$.In the ideal Rayleigh atmosphere $\mathrm{T}_{\mathrm{L}}=1$. The closest to this ideal value $\left(T_{L}=2\right)$ is achieved in clear, cold air at high latitudes.

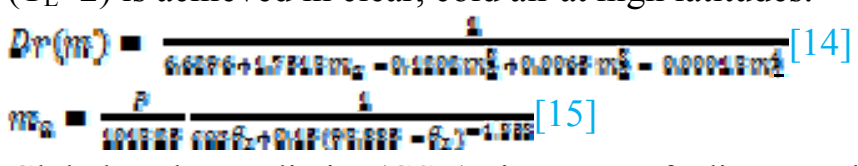

Global solar radiation(GSR) is sum of direct radiation and diffused radiation.Global solar radiation(GSR) and meteorological data are collected from Department of Hydrology and Meteorology(DHM) for year 2012.GSR is measured by CMP6 first class pyranometer[16] shown in Figure 2.Matlab 2015 software is used to analysis and plot graph.Mean ,standard deviation correlation coefficient are used as statistical tools to analysis data. Standard deviation is used as error bar.
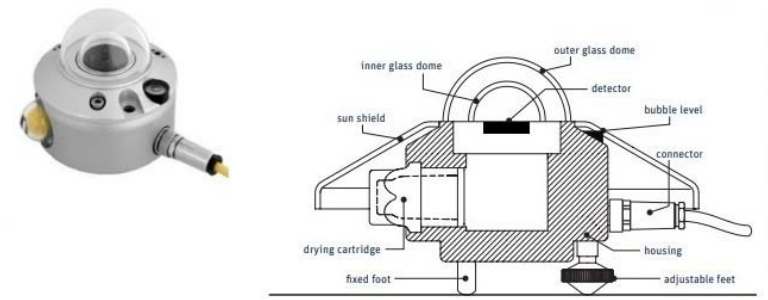

- Thermopile sensor

- GSR (in W/m²)

- $\quad$ Spectral range $=285 \mathrm{~nm}-2800 \mathrm{~nm}$

- Operating temperature $=-40^{0} \mathrm{C}-80^{\circ} \mathrm{C}$

- $\quad$ Field of view $=180^{\circ}$

- Sensitivity $=5-20 \mathrm{mV} /\left(\mathrm{Wm}^{2}\right)$

- Response time $<18$ sec

Figure 2:CMP6 pyranometer [source: www.kippzonen.com]

\section{Results and Discussion}

Figure.2(a) shows monthly variation of clearness index $\left(\mathrm{K}_{\mathrm{T}}\right)$.It is maximum $(0.37 \pm$ 0.08 ) in May due to clear sky and minimum0.27 \pm 0.06 due to fog.Figure. 3(b) shows monthly variation of attenuation coefficient $(\mathrm{K})$.Its maximum is $1.08 \pm 0.18$ in July due to rainy season and minimum $0.61 \pm 0.10$ in January due to clear sky. According to 
Koshmeider's formula,visibility in $\mathrm{km}$ is $\mathrm{R}=3.912 / \mathrm{K}$. Figure 3(c) shows monthly variation of visibility. Visibility is maximum $6.37 \mathrm{~km}$ in January and minimum $3.61 \mathrm{~km}$ in July.
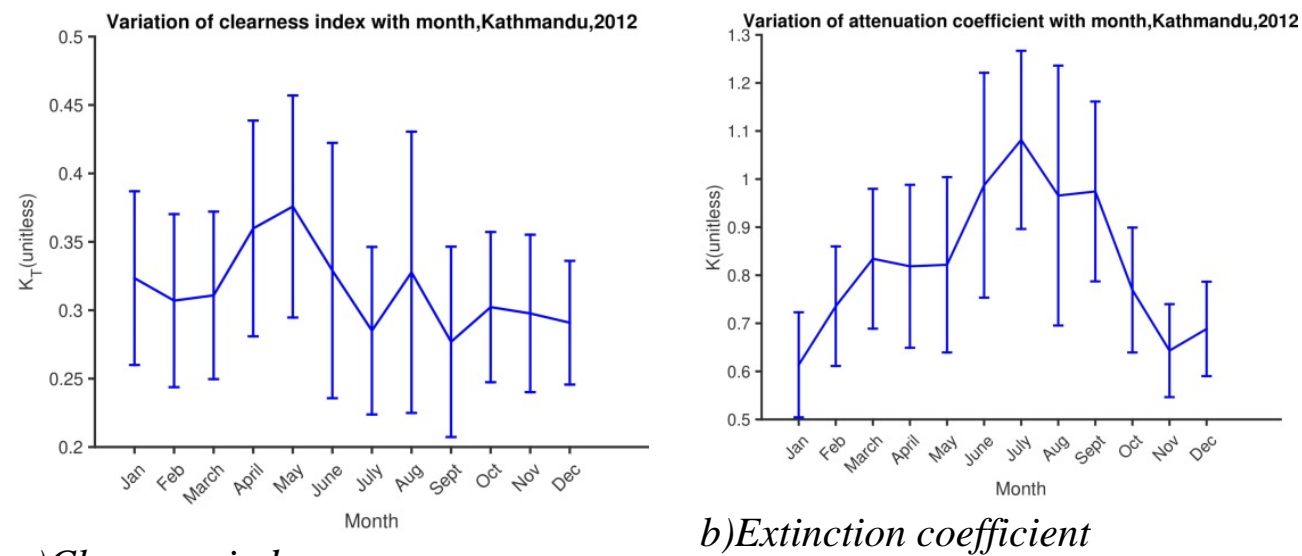

a)Clearness index

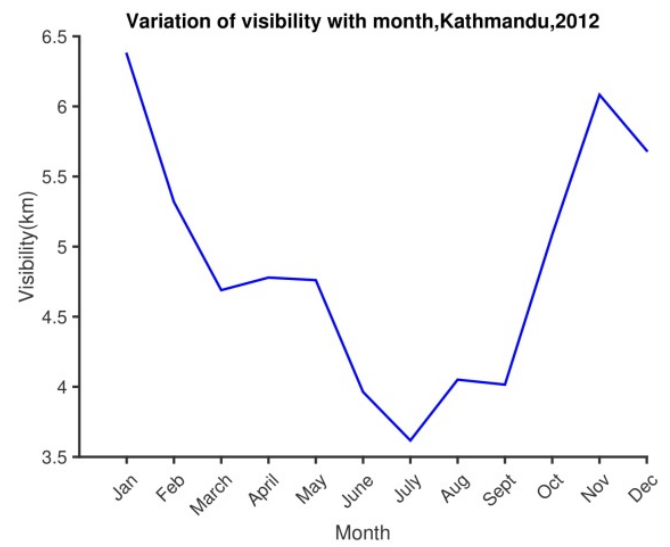

c)Visibility

Figure 3:Monthly variation of parameters

Figure 4(a): show monthly variation of Linke turbidity $\left(\mathrm{L}_{\mathrm{T}}\right)$ with Nepal standard time(NST).Maximum value of Linke turbidity in 9:45 NST,12:45 NST and 15:45 NST are $6.44 \pm 0.34$ in July due to rain, $6.64 \pm 0.56$ in September due to fog and 7.30 \pm 1.21 in August due to rain respectively. Minimum value of Linke turbidity in 9:45 NST,12:45 NST and 15:45 NST are 4.63 \pm 0.42 in January, $4.74 \pm 0.48$ in January and $5.00 \pm 0.40$ in November respectively due to clear day.Figure 4(b) shows monthly variation of Linke turbidity.Maximum value ofLinke turbidity $6.22 \pm 0.32$ is in July and minimum value $4.69 \pm 0.42$ is in January. Its varies less in October whereas large varies in August .Seasonal variation of Linke turbidity is shown in figure 4( c).Its value is maximum in summer and minimum in Winter. 


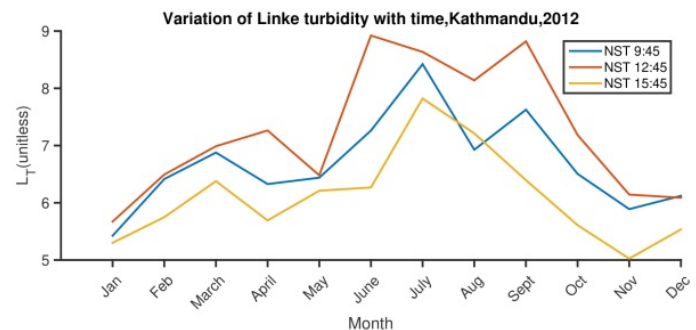

a)Monthly variation of Linke

turbidity with time

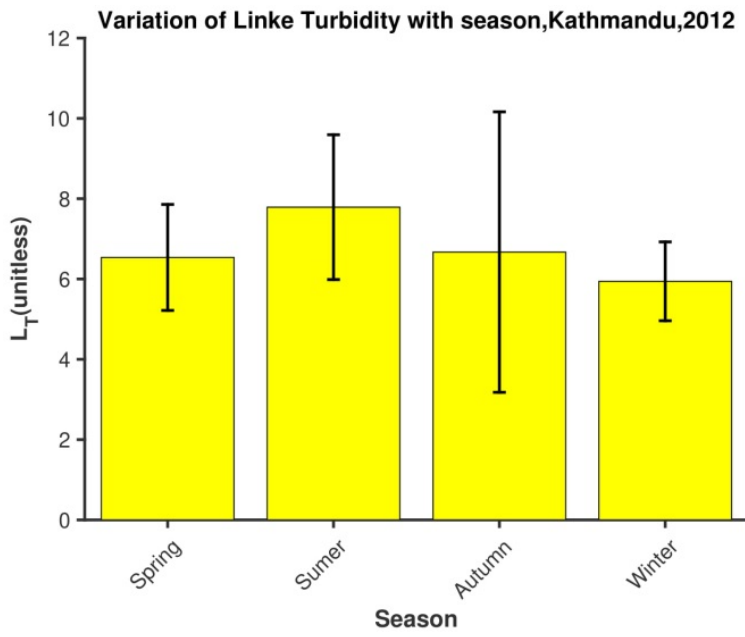

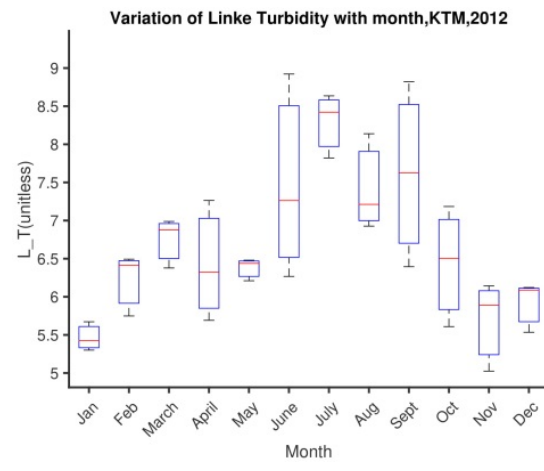

b)Monthly variation of Linke turbidity

c)seasonal variation of Linke

turbidity

Figure 4: Variation of Linke turbidity

Figure $5(\mathrm{a})(\mathrm{b})(\mathrm{c})(\mathrm{d})$ : shows variation of Linke turbidity with maximum temperature, minimum temperature, rainfall and relative humidity(RH).Temperature of hottest day is $35.2{ }^{\circ} \mathrm{C}$ in $165^{\text {th }}$ day of year that of coldest day is $0^{\circ} \mathrm{C}$ in $15^{\text {th }}$ day of year .Number of rainy days is 121 and total rain fall is $1464.7 \mathrm{~mm}$. Annual mean of maximum and minimum temperature are $26.23 \pm 4.96^{\circ} \mathrm{C}$ and $12.38 \pm 6.83^{\circ} \mathrm{C}$ respectively. Annual mean of relative humidity is $74.87 \pm 12.60 \%$. The values of precipitable water content $(\mathrm{w})$ in $\mathrm{cm}$. were estimated using the relative humidity $(\mathrm{RH})$ as a fraction of one and the ambient temperature(T) in Kelvin [17]. $\mathrm{N}$ is day length and $\mathrm{n}$ is sunshine hour. Figure 5(e),(f) shows variation of Linke turbidity with water content, relative sunshine hour $(\mathrm{n} / \mathrm{N})$. Annual mean of relative sunshine hour $(\mathrm{n} / \mathrm{N})$ is $0.57 \pm 0.16$. 
Patan Pragya (Volume: 6, Number: 1 2020)

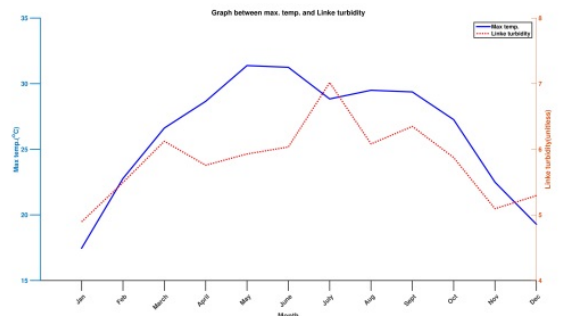

a)Maximum temperature

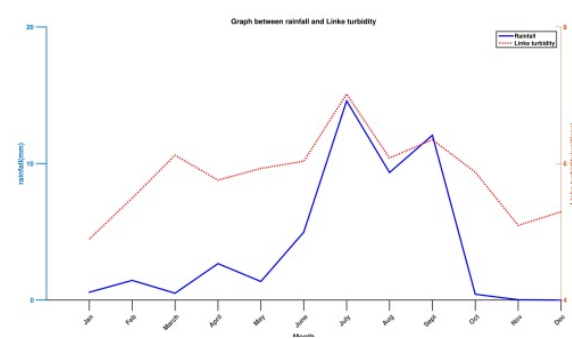

c)Rainfall

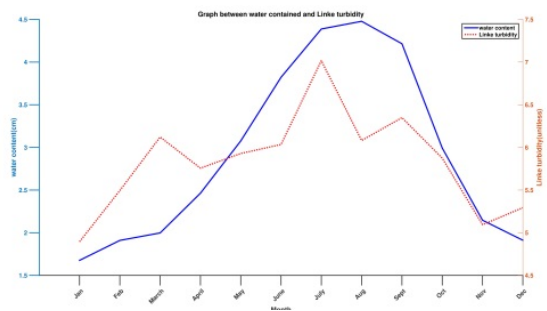

e)Water content

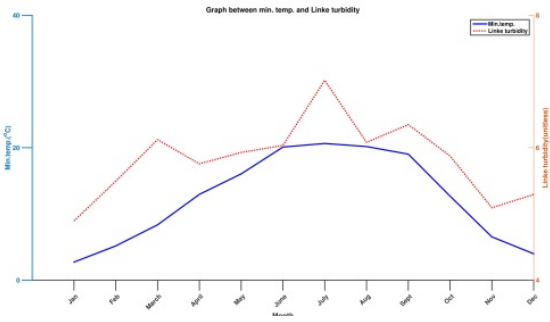

b)Minimum temperature

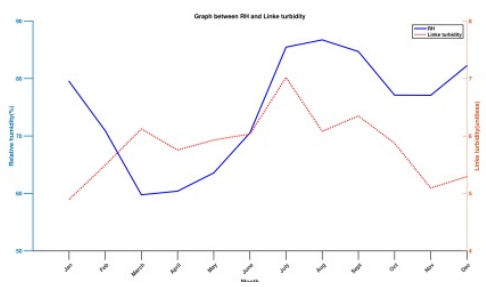

d)Relative humidity

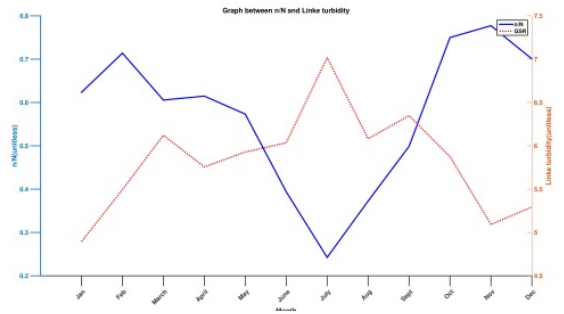

f) Relative sunshine hour

Figure 5:Variation of Linketurbidity with parameters

Correlation coefficient of Linke turbidity with those parameters are shown in Table 1.Effect of maximum temperature ,minimum temperature rainfall and water contained on Linke turbidity is large.But effect of relative humidity on Linke turbidity is not significant. Effect of relative sunshine hour on Linke turbidity is negative.

Table 1:Relation of Linke turbidity with meteorological parameters

\begin{tabular}{|l|l|}
\hline Parameters & Correlation coefficient \\
\hline Maximum temperature & 0.76 \\
\hline Minimum temperature & 0.77 \\
\hline Rainfall & 0.68 \\
\hline Relative Humidity & 0.07 \\
\hline Water content & 0.72 \\
\hline Relative sunshine hour & -0.77 \\
\hline
\end{tabular}




\section{Conclusions}

Annual means clearness index and attenuation coefficient in Kathmandu valley in 2012 are $0.31 \pm 0.14$ and $0.82 \pm 0.14$ respectively. Annual average of Linke turbidity in NST 9:45, $12: 45$ and $15: 45$ are $5.39 \pm 0.50,5.81 \pm 0.51$ and $6.17 \pm 0.78$ respectively. Annual mean of Linke turbidity is $5.82 \pm 0.31$.Minimum temperature mostly affected Linke turbidity where as relative humidity affect less. According to According to Wang at.el[14] ,Linke turbidity values is 3.3 to 7.7 in Wuhan(latitude $30^{\circ} 32^{\prime} \mathrm{N}$, longitude $114^{\circ} 21^{\prime} \mathrm{E}$ and $30 \mathrm{~m}$ a.s.l.), Central China from 2010 to 2011.According to LaxmiNarain and S.N. Garg[18], on eight years(1993-2000)study,Linke turbidity for four cities of India are $T L=7.5$ for Kolkata $\left(26.93^{\circ} \mathrm{N}\right.$, $\left.88.45^{0} \mathrm{E}, 431 \mathrm{masl}\right), T_{L}=4.6$ for Poona $\left(18.53^{0} \mathrm{~N}, 73.85^{0} \mathrm{E}, 559\right.$ masl $), T_{L}=6.4$ for Jaipur $\left(26.93^{0} \mathrm{~N}\right.$, $88.45^{\circ}$ E,431 masl $)$ and $T_{L}=6.8$ for New Delhi $\left(22.65^{\circ} \mathrm{N}, 88.45^{\circ}\right.$ E, 6 masl $)$.A comparison of observedvalues of turbidity parameter with other major cities of the world shows that Kathmandu is as polluted as cities likeJakarta, Kansas, Beijing, Vienna, etc. C2002 Elsevier Science Ltd. All rights reserved.

\section{Acknowledgment}

Authors are grateful to express thank to faculty members of Central Department of Physics, Department of Physics of Patan Multiple Campus, Institute of Science and Technology(IoST),TU, Authors are grateful to express thank to Department of Hydrology and Meteorology(DHM),Government of Nepal on providing data.Authors are highly acknowledged to Nepal Academy of Science and Technology (NAST) for providing PhD fellowship.

\section{References}

[1] Majupuria R K Majupuria T C,Nepal nature's paradise: insight into diverse facets of topography, flora and ecology, M Devi,Gwalior,India, 1999.

[2] JN Shrestha, TR Bajracharya, SRShakya, and BijayGiri. Renewable energy in Nepal progressat a glance from 1998 to 2003, In Proceedings of the International Conference onRenewable Energy Technology for rural Development (RETRUD03), pages 12-14, 2003.

[3] MoF,Economic Survey 2010/011, Ministry of Finance, Government of Nepal, 2010/011.

[4] DTM,Register vehicles till fiscal year BS 2074/075, BS 2075.

[5] CBS,National population and housing census 2011, 2011.

[6] Khem N Poudyal, Binod K Bhattarai, BalkrishnaSapkota, and BeritKjeldstad,Solar radiation potential at four sites of Nepal. Journal of the Institute of Engineering, 8(3): 189-197, 2011. 
Patan Pragya (Volume: 6, Number: 1 2020)

[7] BalkrishnaSapkota and RajanDhaubhadel,Atmospheric turbidity over kathmandu valley. Atmospheric Environment, 36(8):1249-1257, 2002.

[8] Muhammad Iqbal,An introduction to solar radiation. New York: Academic Press, 1983.

[9] Kuo-Nan Liou,An introduction to atmospheric radiation, volume 84. Elsevier, 2002.

[10] Murry L Salby,Physics of the Atmosphere and Climate, Cambridge University Press, 2012.

[11] John A Duffie and William A Beckman,Solar engineering of thermal processes. John Wiley \& Sons, 2013.

[12] Frank Bason. Diffuse solar irradiance and atmospheric turbidity. In Euro Sun 2004 Conference Proceedings, Freiburg,Germany, pages 1-7, 2004.

[13] Elena Eftimie.Linke turbidity factor for brasov urban area. Bulletin of the Transilvania University of Brasov. Engineering Sciences. Series I, 2:61, 2009.

[14] Lunche Wang, Yisen Chen, Ying Niu, Germ'an Ariel Salazar, and Wei Gong, Analysis of atmospheric turbidity in clear skies at wuhan, Central China, Journal of Earth Science, 28(4):729-738, 2017.

[15] John M Wallace and Peter V Hobbs, Atmospheric science: an introductory survey, Volume 92. Elsevier, 2006.

[16] Kipp and Zonen,Instruction manual CMP6 pyranometer, 2008.

[17] M El-Nouby Adam and Eman F El-Nobi, Correlation between air temperature and Atmospheric turbidity at a subtropical location, World Environment, 7(1):1-9, 2017.

[18] Narain, L., \& Garg, S..Estimation of linke turbidity factors fordifferent regions of India. International Journal of Environment andWaste Management, 12(1), 52-64, 2013 